\title{
Atributos físicos, químicos e biológicos do solo impactado por cultivos sucessivos de arroz
}

\author{
Sinnara G. de Godoy' ${ }^{1}$ Luís F. Stone ${ }^{2}$, Enderson P. de B. Ferreira ${ }^{2}$, \\ Tarcísio Cobucci² \& Mábio C. Lacerda²
}

\begin{abstract}
RESUMO
A produtividade do arroz de terras altas sofre queda acentuada quando ele é cultivado durante dois ou mais anos, na mesma área. Este trabalho objetivou determinar quais atributos de um Latossolo Vermelho de Cerrado são mais impactados por cultivos sucessivos de arroz. Em fevereiro de 2011 foram retiradas, em Santo Antônio de Goiás, GO, amostras de solo na camada de 0-0,10 m de três áreas cultivadas, respectivamente, por um, dois e três anos, com arroz em semeadura direta e de uma mata próxima para determinação de atributos físicos, químicos e biológicos do solo. Aplicaram-se técnicas de análise multivariada aos dados obtidos. Os cultivos de arroz provocaram alterações em todos os atributos físicos e na maioria dos atributos químicos e biológicos do solo, quando comparados aos da mata. Os teores de K, Cu e Mn, os quocientes metabólico e microbiano (qmic) e a relação $\mathrm{N}$ da biomassa microbiana: $\mathrm{N}$ total (NBM:N) foram responsáveis por discriminar as áreas de cultivo sucessivo de arroz. Quanto mais anos de cultivos sucessivos de arroz mais as condições do solo diferiram das do solo original da mata. O quociente metabólico aumentou com os anos de cultivo de arroz indicando aumento da condição de estresse ou distúrbio na microbiota do solo.
\end{abstract}

Palavras-chave: Oryza sativa L., semeadura direta, análise multivariada

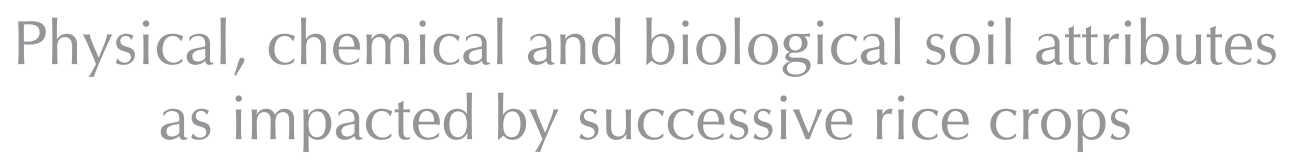

ABSTRACT

Upland rice grain yield sharply decreases when it is grown for two or more years in the same area. This study aimed to determine which attributes of a Cerrado Oxisol are more impacted by successive crops. Samples were taken in February 2011, at Santo Antônio de Goiás, GO, from soil layer of 0-0.10 m of three areas cropped with upland rice under no-tillage system for one, two or three years, respectively, and of a forest for determination of physical, chemical and biological attributes of soil. Multivariate analysis techniques were applied on data obtained in these areas. Rice crops caused changes in all physical attributes of soil and in most of the chemical and biological attributes when compared to the forest. The $\mathrm{K}, \mathrm{Cu}$, and $\mathrm{Mn}$ contents, metabolic and microbial (qmic) quotients and microbial biomass $\mathrm{N}$ :total $\mathrm{N}$ relationship (MBN:N) were responsible for discriminating the areas under successive rice crops. The more the years of successive rice crops, the more the soil conditions differed from the original soil of the forest. The metabolic quotient increased with the years of rice cultivation, which indicates an increase in disorder or stress condition in the soil microbiota.

Key words: Oryza sativa L., no-tillage, multivariate analysis

\footnotetext{
1 Doutoranda do Curso de Pós-Graduação em Agronomia da UFG, CEP 74001-970, Goiânia, GO. Fone: (62) 3534-9801. E-mail: sinnaragodoy@gmail.com ${ }^{2}$ Embrapa Arroz e Feijão, CP 179, CEP 75375-000, Santo Antônio de Goiás, GO. Fone: (62) 3533-2151. E-mail: luis.stone@embrapa.br; enderson.ferreira@embrapa.br; tarcisio.cobucci@embrapa.br; mabio.lacerda@embrapa.br
} 


\section{INTRODUÇÃO}

O cultivo sucessivo do arroz de terras altas na mesma área, não tem sido recomendado devido à queda acentuada da sua produtividade a partir do segundo cultivo (Ventura et al., 1984; George et al., 2002; Fageria \& Baligar, 2003) a despeito das condições favoráveis de água e nutrientes (Ventura et al., 1984; George et al., 2002).

A queda na produtividade do arroz tem sido atribuída a efeitos alelopáticos (Fageria \& Baligar, 2003), definidos como qualquer efeito prejudicial, direto ou indireto, de uma planta sobre outra, por meio da produção de compostos químicos liberados no meio. Em arroz, cujo efeito se faz sentir sobre ele próprio, o termo mais adequado é autotoxicidade (Soares, 2004).

Ventura et al. (1984) constataram, nas Filipinas, que quando resíduos radiculares de arroz coletados em área de cultivo sucessivo deste cereal foram colocados em uma área nova, eles causaram decréscimo na produtividade do arroz, o que não ocorreu quando esses resíduos foram esterilizados. Os autores concluíram, assim, que os danos causados ao arroz por cultivos sucessivos envolvem a presença de microorganismos.

O arroz de terras altas também tem apresentado produtividade aquém da desejada quando cultivado em semeadura direta. Soares (2004) sugeriu que isto se deve ao fato de as plantas de arroz apresentarem, na fase inicial de crescimento, baixa capacidade de redução do nitrato que, em razão das condições favoráveis ao processo de nitrificação, seria a forma de nitrogênio mineral predominante na camada superficial do solo.

No sistema de semeadura direta há revolvimento do solo apenas no sulco de semeadura implicando numa lenta decomposição da matéria orgânica do solo, com consequente liberação lenta de nitrogênio amoniacal. Se este pouco nitrogênio amoniacal produzido na mineralização não for absorvido pela planta será imobilizado pelos microorganismos ou rapidamente nitrificado a nitrato, uma vez que na superfície do solo o meio é rico em oxigênio. Assim, no sistema de semeadura direta o arroz sofre intensa carência de nitrogênio amoniacal em razão da baixa atividade da redutase do nitrato. Esta deficiência afeta bastante o desenvolvimento radicular, o perfilhamento e o desenvolvimento inicial do arroz (Soares, 2004).

Esta hipótese foi confirmada por Araújo et al. (2012) que constataram menor produtividade do arroz de terras altas quando foi fornecido apenas nitrato e a atribuíram ao acúmulo excessivo desta forma nos tecidos das plantas na fase inicial do seu crescimento devido à baixa atividade da redutase do nitrato na fase. As maiores produtividades foram verificadas quando a relação nitrato:amônio esteve entre 75:25 e 78:22.

Outro fator a considerar é o uso do herbicida glifosato na dessecação da palhada na semeadura direta; este herbicida pode alterar a atividade e a composição da comunidade microbiana do solo (Andréa et al., 2003; Zilli et al., 2008), o que pode representar ruptura do equilíbrio biodinâmico no solo interferindo diretamente na decomposição/mineralização da matéria orgânica, na ciclagem de nutrientes e na supressão de doenças, entre outros; ao longo do tempo essas alterações podem representar a perda da qualidade do solo.
Neste contexto, a avaliação conjunta dos atributos físicos, químicos e biológicos do solo é importante para identificar prováveis causas da falta de sustentabilidade de cultivos sucessivos de arroz. Esta avaliação é complexa e deve ser realizada em função de um conjunto de indicadores específicos e suas inter-relações, já que se tem verificado que indicadores isolados não são suficientes para explicar a perda ou o ganho potencial dos cultivos em determinado solo. Assim, a utilização de análise multivariada dos dados poderá indicar diferenças e estabelecer as relações entre os tratamentos e os atributos avaliados, tornando-se uma ferramenta importante na análise das informações obtidas (Cruz-Castilho et al., 1994).

Este trabalho objetivou determinar, com o uso de técnicas de análise multivariada, quais atributos de um Latossolo Vermelho ácrico de Cerrado são mais impactados por cultivos sucessivos de arroz de terras altas em semeadura direta.

\section{Material e Métodos}

O trabalho foi conduzido na Fazenda Capivara, da Embrapa Arroz e Feijão, localizada no município de Santo Antônio de Goiás, GO, compreendida entre as coordenadas $16^{\circ} 31^{\prime} 18^{\prime \prime}$ $\mathrm{S}, 49^{\circ} 18^{\prime} 45^{\prime}$ 'W, $16^{\circ} 31^{\prime} 18^{\prime \prime} \mathrm{S}, 49^{\circ} 16^{\prime} 07^{\prime}$ 'W, $16^{\circ} 29^{\prime} 02^{\prime \prime} \mathrm{S}$, $49^{\circ} 16^{\prime} 07^{\prime \prime} \mathrm{W}, 16^{\circ} 29^{\prime} 02^{\prime \prime} \mathrm{S}$ e $49^{\circ} 18^{\prime} 45^{\prime \prime} \mathrm{W}$, e com altitude média de $823 \mathrm{~m}$. O clima, conforme classificação de Köppen, é Aw, tropical de savana, mega térmico. O regime pluvial é bem definido, com período chuvoso de outubro a abril e seco de maio a setembro, com precipitação média anual de $1485 \mathrm{~mm}$ (Silva et al., 2010). O solo das áreas estudadas é um Latossolo Vermelho ácrico, de textura argilosa, com teores médios de $307 \mathrm{~g} \mathrm{~kg}^{-1}$ de areia, $153 \mathrm{~g} \mathrm{~kg}^{-1}$ de silte e $540 \mathrm{~g} \mathrm{~kg}^{-1}$ de argila, na camada de $0-0,10 \mathrm{~m}$.

A análise química inicial apresentou valores médios semelhantes nesta camada para as áreas estudadas, com $\mathrm{pH}$ $\left(\mathrm{H}_{2} \mathrm{O}\right)=5,4 ; \mathrm{Ca}^{2+}=16,0 \mathrm{mmol}_{\mathrm{c}} \mathrm{dm}^{-3} ; \mathrm{Mg}^{2+}=5,3 \mathrm{mmol}_{\mathrm{c}} \mathrm{dm}^{-3}$; $\mathrm{Al}^{3^{+}}=2,3 \mathrm{mmol}_{\mathrm{c}} \mathrm{dm}^{-3} ; \mathrm{H}^{+}+\mathrm{Al}^{3+}=41,0 \mathrm{mmol}_{\mathrm{c}} \mathrm{dm}^{-3} ; \mathrm{P}=22,4$ $\mathrm{mg} \mathrm{dm}{ }^{-3} ; \mathrm{K}^{+}=92,5 \mathrm{mg} \mathrm{dm}^{-3} ; \mathrm{Cu}^{2+}=1,6 \mathrm{mg} \mathrm{dm}^{-3} ; \mathrm{Zn}^{2+}=5,1 \mathrm{mg}$ $\mathrm{dm}^{-3} ; \mathrm{Fe}^{3+}=27,7 \mathrm{mg} \mathrm{dm}^{-3} ; \mathrm{Mn}^{2+}=12,9 \mathrm{mg} \mathrm{dm}^{-3} ;$ capacidade de troca de cátions a pH $7(\mathrm{CTC})=64,7 \mathrm{mmol}_{\mathrm{c}} \mathrm{dm}^{-3} \mathrm{e}$ saturação por bases $(\mathrm{V})=36,6 \%$. A vegetação original das áreas era do tipo Cerradão.

As áreas estudadas foram cultivadas, respectivamente, por um, dois e três anos com arroz em semeadura direta. Na área de primeiro ano (Área1), o arroz foi semeado sobre a palhada da soja que foi cultivada no ano anterior, em sucessão a dois anos de pastagem de Brachiaria brizantha. A linhagem Primavera CL 431 foi semeada em novembro de 2010, no espaçamento de 0,45 m, após 20 dias da dessecação da palhada com glifosato na dose de $4 \mathrm{~L} \mathrm{ha}^{-1}$.

Nas áreas de segundo (Área 2) e terceiro (Área 3) ano de cultivo sucessivo, o arroz foi semeado sobre as palhadas de milho, milheto, Brachiaria ruzizienses, Brachiaria brizantha e Panicum maximum, semeados em abril do mesmo ano. Antes do primeiro cultivo de arroz, essas áreas vinham sendo cultivadas há seis anos, em semeadura direta, com a rotação milho e soja no verão e pousio no inverno. A linhagem, espaçamento, data e manejo das palhadas, foram os mesmos da área de primeiro ano. A adubação de base foi feita com $20 \mathrm{~kg} \mathrm{ha}^{-1}$ de N, 120 
$\mathrm{kg} \mathrm{ha}^{-1}$ de $\mathrm{P}_{2} \mathrm{O}_{5}, 60 \mathrm{~kg} \mathrm{ha}^{-1}$ de $\mathrm{K}_{2} \mathrm{O}$ e $4 \mathrm{~kg} \mathrm{ha}^{-1}$ de $\mathrm{Zn}$, por meio da aplicação de $400 \mathrm{~kg} \mathrm{ha}^{-1}$ do adubo formulado 5-30-15 com $1 \%$ de $\mathrm{Zn}$; aos 13 dias após a semeadura foram aplicados em cobertura $45 \mathrm{~kg} \mathrm{ha}^{-1}$ de N, na forma de ureia; aos 12 dias da semeadura foi aplicado o herbicida Kifix na dose de $100 \mathrm{~g} \mathrm{ha}^{-1}$ e aos 27 dias foram aplicados o fungicida Brio $\left(0,7 \mathrm{~L} \mathrm{ha}^{-1}\right)$ e o adubo foliar Aminosan $\left(1 \mathrm{~L} \mathrm{ha}^{-1}\right)$, cuja composição é de 112,5 $\mathrm{g} \mathrm{L}^{-1}$ de N; $25,0 \mathrm{~g} \mathrm{~L}^{-1}$ de $\mathrm{P}_{2} \mathrm{O}_{5} ; 12,5 \mathrm{~g} \mathrm{~L}^{-1}$ de $\mathrm{K}_{2} \mathrm{O}$ e $131,2 \mathrm{~g} \mathrm{~L}^{-1}$ de carbono orgânico.

Em fevereiro de 2011 foi realizada amostragem de solo para análises física, química e biológica na camada de 0-0,10 m. Em razão das dimensões de cada área foram amostrados 18 pontos na Área 1, 11 na Área 2 e 10 na Área 3, com quatro repetições ao redor de cada ponto. Também foi amostrado o solo de uma mata próxima ao experimento (Cerradão), representativa da vegetação original, utilizada como referência; nas Áreas 2 e 3 todas as palhadas antecedentes foram consideradas na amostragem.

Os atributos físicos avaliados foram densidade do solo, determinada pelo método do anel volumétrico, porosidade total, pela relação entre a densidade do solo e a densidade de partículas determinada pelo método do balão volumétrico, microporosidade, considerada igual à quantidade de água retida pelo solo na tensão de $6 \mathrm{kPa}$, macroporosidade, pela diferença entre porosidade total e microporosidade, diâmetro médio ponderado dos agregados, determinado via úmida, porcentagem de agregados com diâmetro maior que $2 \mathrm{~mm}$, sendo as análises realizadas segundo EMBRAPA (1997), índice S (Dexter, 2004) e resistência do solo à penetração, determinada com penetrômetro de impacto.

Os atributos químicos avaliados foram o $\mathrm{pH}$ do solo e os teores de $\mathrm{C}, \mathrm{N}, \mathrm{Ca}^{2+}, \mathrm{Mg}^{2+}, \mathrm{Al}^{3+}, \mathrm{H}^{+}+\mathrm{Al}^{3+}, \mathrm{P}, \mathrm{K}^{+}, \mathrm{Cu}^{2+}, \mathrm{Zn}^{2+}$, $\mathrm{Fe}^{3+} \mathrm{e} \mathrm{Mn}^{2+}$, e calculados a capacidade de troca de cátions a pH 7 e a saturação por bases; o $\mathrm{pH}$ foi determinado em água. $\mathrm{O}$ carbono e o nitrogênio total do solo foram determinados pelo método de combustão a seco no analisador elementar CHNS/O Perkin-Elmer modelo 2400 Series II. $\mathrm{OAl}^{3+}, \mathrm{Ca}^{2+} \mathrm{e} \mathrm{Mg}^{2+}$ foram extraídos em $\mathrm{KCl}$ a $1 \mathrm{~N}$, sendo o primeiro determinado por titulação com $\mathrm{NaOH} 0,025 \mathrm{~N}$ e os dois últimos por titulação de EDTA.O $\mathrm{H}^{+}+\mathrm{Al}^{3+}$ foi determinado por titulometria, usando-se solução de acetato de cálcio $1 \mathrm{~N}$ a $\mathrm{pH} 7$ para sua extração. $\mathrm{O}$ fósforo e o potássio foram extraídos com a solução de Mehlich 1 ( $\mathrm{HCl}$ a $0,5 \mathrm{~N}+\mathrm{H}_{2} \mathrm{SO}_{4}$ a $0,025 \mathrm{~N}$ ) e determinados em colorímetro e fotômetro de chama, respectivamente. Os micronutrientes foram determinados em espectrofotômetro de absorção atômica utilizando-se o extrator Mehlich 1. As análises laboratoriais foram realizadas de acordo com EMBRAPA (1997).

Os atributos biológicos avaliados foram carbono orgânico total do solo (COT), determinado pelo método de Walkley \& Black (EMBRAPA, 1997), carbono (CBM) e nitrogênio (NBM) da biomassa microbiana determinados, respectivamente, pelo método da fumigação-extração e pelo método de Kjeldhal, respiração basal do solo (RBS), determinada pela quantificação do $\mathrm{CO}_{2}$ liberado durante a incubação do solo em sistema fechado, quocientes metabólico $\left(\mathrm{qCO}_{2}\right)$, obtido pela relação entre RBS e CBM, e microbiano (qmic), obtido pela relação entre CBM e COT, relação NBM:N total, atividade enzimática total do solo (AET) pelo método de hidrólise do diacetato de fluoresceína, atividades da $\beta$-glicosidase (ABG) e da fosfatase ácida (AFA) pelo método da determinação colorimétrica do p-nitrofenol, liberado pelas enzimas, quando o solo é incubado com os substratos específicos p-nitrofenil-beta-Dglicopironosídeo e p-nitrofenil-fosfato, respectivamente. Mais detalhes sobre a determinação desses atributos são apresentados em Ferreira et al. (2011).

Para cada atributo estudado foram calculados a média e o erro padrão pela estatística descritiva clássica e se estabeleceram correlações entre eles. A técnica multivariada foi utilizada por meio da análise de componentes principais envolvendo todas as áreas e atributos em estudo, a partir da qual foi reduzido o conjunto de dados em combinações lineares, gerando escores dos componentes principais que explicam em torno de $80 \%$ da variação total, conforme recomendado por Cruz \& Regazzi (1994). Isto permitiu identificar os atributos mais relevantes na discriminação das áreas; adicionalmente, efetuou-se a análise de agrupamento pelo método de Ward; a medida de dissimilaridade utilizada foi a distância euclidiana média; as análises multivariadas foram feitas com o auxílio do Programa R (R Development Core Team, 2011).

\section{Resultados E Discussão}

A análise de componentes principais mostrou que a variância acumulada nos primeiros dois componentes foi de $94,8 \%$, tendo o primeiro componente explicado $79,0 \%$ da variância total e o segundo 15,8\% (Tabela 1).

Com exceção dos teores de potássio e cobre, dos quocientes metabólico e microbiano e da relação NBM:N total (Tabela 1), todos os demais atributos do solo propiciaram altos índices de correlação com o primeiro componente principal ( $r>|0,60|)$ e foram responsáveis por discriminar as áreas de cultivo de arroz em relação à mata.

Todos os atributos físicos foram impactados negativamente com a mudança do uso do solo sob vegetação de Cerrado para a produção agrícola. Araújo et al. (2007) também verificaram, comparando a qualidade do solo em área de Cerrado nativo e em áreas sob diferentes usos, que os atributos físicos do solo foram os mais afetados pelos tipos de usos avaliados. As alterações físicas podem influenciar na maioria dos fenômenos importantes que ocorrem no solo, incluindo a quantidade de calor, água e gases transportados e sua resistência mecânica.

O solo sob mata, por não sofrer o trânsito de máquinas e equipamentos, apresentou menores valores de densidade e microporosidade e maiores valores de macroporosidade e porosidade total em relação aos solos cultivados (Tabela 2), concordando com os resultados de Silva et al. (2008) e Andrade et al. (2009). Verificaram-se, ainda, maiores diâmetro médio ponderado dos agregados e porcentagem de agregados com diâmetro maior que $2 \mathrm{~mm}$ no solo da mata, o que concorda com os resultados obtidos por Silva et al. (2008), que constataram maior agregação nos sistemas em equilíbrio com maiores teores de matéria orgânica e boa diversidade e atividade microbiana na massa do solo.

A maior densidade dos solos cultivados se refletiu na sua maior resistência à penetração (RP) em relação ao solo sob mata (Tabela 2). Carneiro et al. (2009) também observaram menor RP em solo sob mata em relação aos solos cultivados. O solo 
Tabela 1. Correlação entre cada componente principal e os atributos físicos, químicos e biológicos da camada de 0-0,10 m do Latossolo Vermelho ácrico submetido a diversos usos

\begin{tabular}{|c|c|c|}
\hline Atributos & $\mathrm{CP}^{1}{ }^{1}$ & CP2 \\
\hline Densidade do solo $\left(\mathrm{Mg} \mathrm{m}^{-3}\right)$ & $-0,95$ & 0,30 \\
\hline Porosidade total $\left(\mathrm{m}^{3} \mathrm{~m}^{-3}\right)$ & 0,95 & $-0,30$ \\
\hline Microporosidade $\left(\mathrm{m}^{3} \mathrm{~m}^{-3}\right)$ & $-0,98$ & $-0,14$ \\
\hline Macroporosidade $\left(\mathrm{m}^{3} \mathrm{~m}^{-3}\right)$ & 0,99 & $-0,11$ \\
\hline Agregados com diâmetro $>2 \mathrm{~mm}(\%)$ & 0,98 & $-0,05$ \\
\hline Diâmetro médio ponderado dos agregados $(\mathrm{mm})$ & 0,96 & $-0,20$ \\
\hline Resistência do solo à penetração (MPa) & $-0,97$ & 0,08 \\
\hline Índice S & 0,91 & $-0,41$ \\
\hline Carbono total $\left(\mathrm{g} \mathrm{kg}^{-1}\right)$ & 0,99 & $-0,08$ \\
\hline Nitrogênio total $\left(\mathrm{g} \mathrm{kg}^{-1}\right)$ & 0,98 & 0,21 \\
\hline pH em água & $-0,95$ & 0,28 \\
\hline Teor de cálcio trocável $\left(\mathrm{mmol}_{\mathrm{c}} \mathrm{dm}^{-3}\right)$ & $-0,90$ & 0,43 \\
\hline Teor de magnésio trocável $\left(\mathrm{mmol}_{\mathrm{c}} \mathrm{dm}^{-3}\right)$ & $-0,76$ & 0,56 \\
\hline Teor de alumínio trocável $\left(\mathrm{mmol}_{\mathrm{c}} \mathrm{dm}^{-3}\right)$ & 0,98 & $-0,19$ \\
\hline Teor de $\mathrm{H}^{+}+\mathrm{Al}^{3+}\left(\mathrm{mmol}_{\mathrm{c}} \mathrm{dm}^{-3}\right)$ & 0,97 & $-0,23$ \\
\hline Teor de fósforo disponível $\left(\mathrm{mg} \mathrm{dm}^{-3}\right)$ & $-0,98$ & $-0,05$ \\
\hline Teor de potássio disponível $\left(\mathrm{mg} \mathrm{dm}^{-3}\right)$ & $-0,21$ & $-0,65$ \\
\hline Teor de cobre disponível ( $\mathrm{mg} \mathrm{dm}^{-3}$ ) & 0,35 & 0,69 \\
\hline Teor de zinco disponível $\left(\mathrm{mg} \mathrm{dm}^{-3}\right)$ & $-0,97$ & $-0,24$ \\
\hline Teor de ferro disponível $\left(\mathrm{mg} \mathrm{dm}^{-3}\right)$ & 1,00 & $-0,03$ \\
\hline Teor de manganês disponível ( $\mathrm{mg} \mathrm{dm}^{-3}$ ) & 0,69 & 0,72 \\
\hline Capacidade de troca catiônica $\left(\mathrm{mmol}_{\mathrm{c}} \mathrm{dm}^{-3}\right)$ & 1,00 & $-0,07$ \\
\hline Saturação por bases (\%) & $-0,93$ & 0,35 \\
\hline Carbono orgânico total $\left(\mathrm{mg} \mathrm{kg}^{-1}\right)$ & 1,00 & 0,03 \\
\hline Carbono da biomassa microbiana - CBM $\left(\mathrm{mg} \mathrm{kg}^{-1}\right)$ & 0,87 & 0,42 \\
\hline Nitrogênio da biomassa microbiana - NBM (mg kg-1) & 0,86 & 0,49 \\
\hline Atividade enzimática total $\left(\mu \mathrm{g}\right.$ FDA g solo $\left.\sec 0^{-1} \mathrm{~h}^{-1}\right)$ & 0,99 & 0,16 \\
\hline Atividade da $\beta$-glicosidase ( $\mu \mathrm{g}$ p-nitrofenol $\mathrm{g}^{-1}$ solo seco $\mathrm{h}^{-1}$ ) & $-0,97$ & 0,21 \\
\hline Atividade da fosfatase ácida ( $\mu \mathrm{g} \mathrm{p}$-nitrofenol $\mathrm{g}^{-1}$ solo seco $\mathrm{h}^{-1}$ ) & 0,99 & 0,14 \\
\hline Respiração basal do solo $\left(\mathrm{mg} \mathrm{C}-\mathrm{CO}_{2} \mathrm{~kg}^{-1} \mathrm{~h}^{-1}\right)$ & 0,98 & $-0,11$ \\
\hline 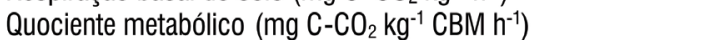 & $-0,29$ & $-0,94$ \\
\hline Quociente microbiano (\%) & 0,60 & 0,65 \\
\hline Relação NBM:N total (\%) & 0,55 & 0,79 \\
\hline
\end{tabular}

Tabela 2. Média e erro padrão dos atributos físicos na camada de 0-0,10 m do Latossolo Vermelho ácrico submetido a diversos usos

\begin{tabular}{lccccc}
\hline \multicolumn{1}{c}{ Atributo } & & Mata & Área 1 & Área 2 & Área 3 \\
Densidade do solo & Média & 1,000 & 1,290 & 1,230 & 1,260 \\
$\left(\mathrm{Mg} \mathrm{m}^{-3}\right)$ & EPM $^{2}$ & 0,024 & 0,015 & 0,010 & 0,025 \\
Porosidade total & Média & 0,624 & 0,518 & 0,538 & 0,527 \\
$\left(\mathrm{~m}^{3} \mathrm{~m}^{-3}\right)$ & EPM & 0,009 & 0,006 & 0,004 & 0,009 \\
Microporosidade & Média & 0,309 & 0,363 & 0,384 & 0,393 \\
$\left(\mathrm{~m}^{3} \mathrm{~m}^{-3}\right)$ & EPM & 0,007 & 0,004 & 0,003 & 0,004 \\
$\mathrm{Macroporosidade}$ & Média & 0,315 & 0,155 & 0,154 & 0,135 \\
$\left(\mathrm{~m}^{3} \mathrm{~m}^{-3}\right)$ & EPM & 0,016 & 0,008 & 0,004 & 0,013 \\
Agregados com & Média & 96,70 & 66,40 & 61,80 & 66,20 \\
diâmetro $>2 \mathrm{~mm}(\%)$ & EPM & 1,099 & 2,171 & 3,551 & 2,512 \\
Diâmetro médio ponderado & Média & 11,80 & 6,70 & 6,80 & 7,40 \\
dos agregados (mm) & EPM & 0,357 & 0,385 & 0,568 & 0,428 \\
Resistência do solo & Média & 0,850 & 1,41 & 1,48 & 1,37 \\
à penetração (MPa) & EPM & 0,034 & 0,040 & 0,055 & 0,079 \\
Índice S & Média & 0,074 & 0,043 & 0,053 & 0,047 \\
& EPM & 0,006 & 0,002 & 0,002 & 0,003 \\
\hline
\end{tabular}

${ }^{1}$ Áreas 1, 2 e 3 - áreas cultivadas com arroz, respectivamente, por um, dois e três anos EPM - erro padrão da média

sob mata apresentou maior índice $\mathrm{S}$ que os solos das demais áreas, indicando melhor qualidade física, o que concorda com os resultados de Silva et al. (2008) e Andrade et al. (2009).
O nitrogênio do solo se encontra quase que totalmente complexado na forma orgânica (98\%) dependendo da biomassa microbiana do solo para sua transformação e consequente absorção pelas plantas (Coser et al., 2007). Ademais, o nitrogênio mineral adicionado de fertilizantes, não é incorporado à fração do nitrogênio total do solo, ao contrário do nitrogênio orgânico, que advém da decomposição de resíduos orgânicos. Além disto, aproximadamente $60 \%$ da matéria orgânica do solo são compostos pelo carbono proveniente do material vegetal em diferentes estágios de decomposição e evolução (Siqueira Neto et al., 2009). Assim, o grande e constante aporte de resíduos orgânicos no solo sob mata e a maior atividade microbiana são causas, provavelmente, dos maiores teores de nitrogênio e carbono total nesse solo em relação aos das áreas cultivadas (Tabela 3). Siqueira Neto et al. (2009) também observaram maior teor de carbono total em solo sob Cerradão do que em solos cultivados.

Os Latossolos do Cerrado são, na sua quase totalidade, ácidos (Souza et al., 2008); assim, o solo sob mata, por não ter recebibo calcário, apresentou menores valores de $\mathrm{pH}$ e do teor de cálcio e maiores teores de alumínio e acidez trocável (Tabela 3) que as áreas cultivadas, como consequência a sua saturação por bases foi menor.

O alumínio ocupa a maior parte de capacidade de troca catiônica dos Latossolos de Cerrado (Souza et al., 2008) e a matéria orgânica é responsável por 75 a 85\% da CTC desses

Tabela 3. Média e erro padrão dos atributos químicos na camada de 0-0,10 m do Latossolo Vermelho ácrico submetido a diversos usos

\begin{tabular}{|c|c|c|c|c|c|}
\hline Atributo & & Mata & Área $1^{1}$ & Área 2 & Área 3 \\
\hline Carbono total & Média & 39,8 & 25,4 & 24,2 & 25,0 \\
\hline$\left(\mathrm{g} \mathrm{kg}^{-1}\right)$ & $\mathrm{EPM}^{2}$ & 3,029 & 0,580 & 0,820 & 0,436 \\
\hline Nitrogênio total & Média & 2,8 & 2,1 & 1,8 & 1,8 \\
\hline$\left(\mathrm{g} \mathrm{kg}^{-1}\right)$ & EPM & 0,193 & 0,051 & 0,062 & 0,046 \\
\hline \multirow[b]{2}{*}{ pH em água } & Média & 5,00 & 5,57 & 5,44 & 5,59 \\
\hline & EPM & 0,147 & 0,065 & 0,057 & 0,078 \\
\hline Teor de cálcio & Média & 10,0 & 26,5 & 20,8 & 24,5 \\
\hline trocável $\left(\mathrm{mmol}_{\mathrm{C}} \mathrm{dm}^{-3}\right)$ & EPM & 4,378 & 1,138 & 1,175 & 1,349 \\
\hline Teor de magnésio & Média & 6,3 & 11,1 & 8,1 & 10,8 \\
\hline trocável $\left(\mathrm{mmol}_{\mathrm{c}} \mathrm{dm}^{-3}\right)$ & EPM & 2,394 & 0,517 & 0,551 & 0,682 \\
\hline Teor de alumínio & Média & 7,8 & 0,5 & 1,0 & 0,4 \\
\hline trocável $\left(\mathrm{mmol}_{\mathrm{c}} \mathrm{dm}^{-3}\right)$ & EPM & 1,652 & 0,152 & 0,203 & 0,094 \\
\hline Teor de $\mathrm{H}^{+}+\mathrm{Al}^{3+}$ & Média & 93,3 & 46,5 & 52,9 & 45,5 \\
\hline$\left(\mathrm{mmol}_{\mathrm{c}} \mathrm{dm}^{-3}\right)$ & EPM & 5,721 & 2,151 & 2,096 & 1,886 \\
\hline Teor de fósforo & Média & 1,5 & 13,1 & 16,6 & 14,1 \\
\hline disponível (mg dm³) & EPM & 0,229 & 1,560 & 2,154 & 2,506 \\
\hline Teor de potássio & Média & 78,5 & 76,0 & 84,2 & 85,5 \\
\hline disponível (mg dm-3) & EPM & 10,851 & 5,506 & 6,984 & 9,159 \\
\hline Teor de cobre & Média & 1,83 & 2,07 & 1,70 & 1,40 \\
\hline disponível (mg dm${ }^{-3}$ ) & EPM & 0,048 & 0,079 & 0,060 & 0,036 \\
\hline Teor de zinco & Média & 0,88 & 3,02 & 4,46 & 4,06 \\
\hline disponível (mg dm-3) & EPM & 0,165 & 0,290 & 0,353 & 0,195 \\
\hline Teor de ferro & Média & 107,8 & 41,8 & 33,8 & 28,7 \\
\hline disponível (mg dm³) & EPM & 7,568 & 1,906 & 0,866 & 1,067 \\
\hline Teor de manganês & Média & 49,2 & 48,9 & 16,9 & 23,5 \\
\hline disponível (mg dm-3) & EPM & 14,939 & 1,669 & 0,793 & 1,118 \\
\hline Capacidade de troca & Média & 111,5 & 86,0 & 84,1 & 82,8 \\
\hline catiônica $\left(\mathrm{mmol}_{\mathrm{c}} \mathrm{dm}^{-3}\right)$ & EPM & 12,285 & 1,474 & 2,036 & 1,828 \\
\hline Saturação por bases (\%) & Média & 14,9 & 46,1 & 37,2 & 45,0 \\
\hline 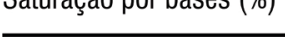 & EPM & 4,401 & 1,890 & 1,714 & 1,972 \\
\hline
\end{tabular}

${ }^{1}$ Áreas 1,2 e 3 - áreas cultivadas com arroz, respectivamente, por um, dois e três anos

2 EPM - erro padrão da média 
solos (Siqueira Neto et al., 2009). Ademais, a correlação entre carbono total e CTC foi positiva e altamente significativa $(\mathrm{r}=$ $0,85 ; p<0,01)$, concordando com os resultados de Siqueira Neto et al. (2009). Desta forma e como os teores de alumínio e de carbono total foram maiores no solo da mata, a CTC também foi maior neste solo em relação às áreas cultivadas.

Originalmente, os teores de fósforo dos Latossolos são muito baixos e os de zinco são baixos (Souza et al., 2008) e, como o solo sob mata não foi adubado, seus teores de fósforo e zinco foram menores em relação às áreas cultivadas uma vez que os adubos usados nessas áreas, além dos macronutrientes nitrogênio, fósforo e potássio, continham zinco na sua composição.

$\mathrm{O}$ teor de ferro, por sua vez, foi maior no solo sob mata devido, sem dúvida, ao $\mathrm{pH}$ mais ácido; a correlação entre $\mathrm{pH}$ e teor de ferro foi significativa e negativa $(r=-0,50 ; p<0,01)$, concordando com os resultados de Alleoni et al. (2005) e/ou a maior ciclagem do ferro pela matéria orgânica, uma vez que a correlação entre o teor desse micronutriente e o COT foi significativa e positiva $(r=0,52 ; p<0,01)$ e o COT foi maior na mata.

O maior teor de carbono orgânico total sob mata do que nos solos cultivados com arroz (Tabela 4) foi devido, quiçá, ao grande aporte de resíduos orgânicos, como já discutido, concordando com os resultados de Jakelaitis et al. (2008) e Pôrto et al. (2009). De acordo com Jakelaitis et al. (2008), a diminuição no carbono orgânico total nos solos sob cultivo pode ser devida também ao aumento no consumo do carbono prontamente disponível pela biomassa microbiana e, ainda, pelo manejo adotado.

Tabela 4. Média e erro padrão dos atributos biológicos na camada de 0-0,10 m do Latossolo Vermelho ácrico submetido a diversos usos

\begin{tabular}{|c|c|c|c|c|c|}
\hline \multicolumn{2}{|l|}{ Atributo } & Mata & \multicolumn{3}{|c|}{ Área $1^{1}$ Área 2 Área 3} \\
\hline Carbono orgânico & Média & 18,7 & 14,5 & 13,6 & 13,7 \\
\hline total & $\mathrm{E}$ & 1,440 & 0,358 & 0,403 & 0,335 \\
\hline Carbono da biomassa & Média & 299,8 & 250,0 & 173,6 & 145,2 \\
\hline microbiana - CBM $\left(\mathrm{mg} \mathrm{kg}^{-1}\right)$ & EPM & 23,030 & 19,158 & 8,190 & 10,977 \\
\hline Nitrogênio da biomassa & Média & 47,5 & 38,2 & 20,0 & 26,0 \\
\hline - NBM $\left(\mathrm{mg} \mathrm{kg}^{-1}\right)$ & EPM & 6,020 & 1,780 & 0,859 & 2,493 \\
\hline Atividade enzimática total & Média & 177,3 & 106,0 & 73,7 & 75,5 \\
\hline$\left(\mu \mathrm{g}\right.$ FDA g solo seco-1 $\left.\mathrm{h}^{-1}\right)$ & EPM & 20,129 & 6,226 & 4,587 & 5,016 \\
\hline Atividade da $\beta$-glicosidase & Média & 33,6 & 64,6 & 60,4 & 67,0 \\
\hline$\left(\mu \mathrm{g} \mathrm{p}\right.$-nitrofenol $\mathrm{g}^{-1}$ solo seco $\left.\mathrm{h}^{-1}\right)$ & EPM & 5,465 & 2,644 & 4,904 & 2,92 \\
\hline Atividade da fosfatase ácida & Média & 805,8 & 406,2 & 236,5 & 270,0 \\
\hline$\left(\mu \mathrm{g} \mathrm{p}\right.$-nitrofenol $\mathrm{g}^{-1}$ solo seco $\left.\mathrm{h}^{-1}\right)$ & EPM & 129,601 & 15,742 & 17,598 & 8,238 \\
\hline Respiração basal do solo & Média & 2,02 & 1,31 & 1,35 & 1,10 \\
\hline$\left(\mathrm{mg} \mathrm{C}-\mathrm{CO}_{2} \mathrm{~kg}^{-1} \mathrm{~h}^{-1}\right)$ & EPI & 0,220 & 0,079 & 0,090 & 0,091 \\
\hline Quociente metabólico & Média & 7,03 & 5,76 & 8,20 & 8,03 \\
\hline (mg C-C & EP & 1,331 & 0,403 & 0,545 & 0,807 \\
\hline rabi & Média & 1,63 & 1,71 & 1,29 & 1,06 \\
\hline roblan & EPM & 0,178 & 0,116 & 0,061 & 0,082 \\
\hline & Média & 1,73 & 1,79 & 1,15 & 1,47 \\
\hline$\sqrt{\text { total }}$ & EPM & 0,247 & 0,077 & 0,041 & 0,126 \\
\hline
\end{tabular}

${ }^{1}$ Áreas 1, 2 e 3 - áreas cultivadas com arroz, respectivamente, por um, dois e três anos ${ }^{2}$ EPM - erro padrão da média

Os teores de carbono e nitrogênio da biomassa microbiana no solo sob mata também foram maiores que nos solos cultivados com arroz (Tabela 4), concordando com os resultados de Pôrto et al. (2009) e Ferreira et al. (2011). O maior valor de CBM e NBM na mata é reflexo de uma situação particular para a microbiota do solo neste sistema, que é estimulado pelo fornecimento contínuo de materiais orgânicos com diferentes graus de susceptibilidade à decomposição, originados da vegetação (Ferreira et al., 2011).

A diversidade das espécies vegetais da mata nativa, notadamente maior que dos sistemas agrícolas avaliados, implica em deposição na serapilheira de substratos orgânicos oxidáveis com composição variada. Além disto, existe maior diversidade de compostos orgânicos depositados na rizosfera, o que constitui fator favorável à sobrevivência e ao crescimento de diferentes grupos de micro-organismos do solo. Neste sentido, a abundância de micro-organismos decompositores pode contribuir para estimular também sua microfauna saprófita e predadora; assim, as condições distintas do solo sob vegetação de mata, juntamente com a ausência de perturbações decorrentes de atividade antrópica, tornam possível a existência de maiores quantidades de CBM e NBM, indicando o maior equilíbrio da microbiota do solo no ecossistema (Pôrto et al., 2009; Ferreira et al., 2011). Nunes et al. (2009) verificaram, por meio de análise multivariada, que entre os atributos biológicos do solo o CBM foi o que mais contribuiu para a separação da mata de áreas sob diversos usos.

A atividade enzimática total e a atividade da fosfatase ácida foram maiores e a atividade da $\beta$-glicosidase foi menor no solo sob mata em relação ao sob cultivo (Tabela 4), concordando com os resultados de Ferreira et al. (2011). De acordo com esses autores, a AET e a AFA são maiores na presença de altos teores de CBM. Realmente, neste trabalho as correlações entre AET e CBM e entre AFA e CBM foram positivas e significativas (respectivamente, $r=0,69 ; p<0,01$ e $r=0,68 ; p<0,01)$. A correlação entre a $\mathrm{ABG}$ e $\mathrm{CBM}$ não foi significativa, concordando com Ferreira et al. (2011). Isto demonstra a importância da fosfatase ácida na mineralização do fósforo orgânico em áreas sob vegetação nativa, onde a matéria orgânica é a principal fonte de nutrientes para o crescimento das plantas. A menor atividade da $\beta$-glicosidase no solo sob mata foi devida, possivelmente, à maior diversidade de espécies vegetais e, consequentemente, da maior complexidade dos resíduos vegetais que atingem a superfície do solo uma vez que esta enzima atua na etapa final do processo de decomposição da celulose.

A respiração basal foi maior no solo da mata concordando com Jakelaitis et al. (2008) e Carneiro et al. (2009); a maior liberação de $\mathrm{CO}_{2}$ geralmente se deve à maior atividade biológica que, por sua vez, está relacionada diretamente com a quantidade de carbono lábil existente no solo.

Os atributos do solo que propiciaram os maiores índices de correlação com o segundo componente principal $(r>|0,60|)$ foram os teores de potássio, cobre e manganês, os quocientes metabólico e microbiano e a relação NBM:N. Esses atributos foram responsáveis por discriminar as áreas de cultivo sucessivo de arroz.

A maior produtividade média do arroz cultivado na área de primeiro ano $\left(2266 \mathrm{~kg} \mathrm{ha}^{-1} \pm 339 \mathrm{~kg} \mathrm{ha}^{-1}\right)$ em relação às áreas de segundo ( $\left.628 \mathrm{~kg} \mathrm{ha}^{-1} \pm 129 \mathrm{~kg} \mathrm{ha}^{-1}\right)$ e de terceiro ano $\left(712 \mathrm{~kg} \mathrm{ha}^{-1}\right.$ $\left.\pm 200 \mathrm{~kg} \mathrm{ha}^{-1}\right)$ deve ter resultado em maior extração de potássio naquela área e contribuído para a discriminar das demais áreas. 
Os teores de cobre e manganês no solo da área de primeiro ano de cultivo de arroz foram maiores que nos solos das áreas de segundo e terceiro anos de cultivo (Tabela 3). O glifosato forma compostos insolúveis com vários metais, inclusive com o cobre e o manganês (Coutinho \& Mazo, 2005). O maior número de aplicações desse herbicida nas áreas de segundo e terceiro cultivos de arroz pode ter contribuído para a redução do teor desses elementos no solo. Ademais, Huber (2007) constatou que o glifosato causou decréscimo na população de organismos redutores e aumento na de oxidantes de manganês na rizosfera da soja. A maior população de organismos oxidantes favoreceu a transformação do $\mathrm{Mn}^{2+}$, forma ativa, absorvível pelas plantas, em $\mathrm{Mn}^{4+}$, forma inativa, não absorvível pelas plantas causando, como consequência, deficiência de Mn na soja. Realmente, as condições mais favoráveis à atividade microbiana na área de primeiro ano, expressa pelo maior valor de qmic e menor de $\mathrm{qCO}_{2}$ (Tabela 4), devem ter influenciado a ciclagem do cobre e do manganês, visto que a correlação desses micronutrientes com qmic foi positiva $(r=0,59 ; p<0,01$ e $r=0,49 ; p<0,01$, respectivamente) e com $\mathrm{qCO}_{2}$ foi negativa $(\mathrm{r}=-0,46 ; \mathrm{p}<0,01$ e $r=-0,48 ; p<0,01$, respectivamente).

O quociente metabólico foi menor e o quociente microbiano e a relação NBM:N total foram maiores na área de primeiro ano de cultivo de arroz em relação às áreas de segundo e terceiro cultivos (Tabela 4).

Valores elevados de $\mathrm{qCO}_{2}$ são indicativos de ecossistemas submetidos a alguma condição de estresse ou distúrbio (Carneiro et al., 2009; Pôrto et al., 2009). À medida que a biomassa microbiana se torna mais eficiente na utilização de recursos do ecossistema, menos $\mathrm{CO}_{2}$ é perdido pela respiração e maior proporção de carbono é incorporada aos tecidos microbianos, o que resulta em diminuição do $\mathrm{qCO}_{2}$. Menores valores de $\mathrm{qCO}_{2}$ indicam agroecossistemas mais estáveis.

Zilli et al. (2008) constataram alterações na comunidade microbiana do solo com o uso do herbicida glifosato. Essas alterações, embora muitas vezes sejam consideradas temporárias, podem representar ruptura do equilíbrio biodinâmico no solo, interferindo diretamente na decomposição/mineralização da matéria orgânica, ciclagem de nutrientes e supressão de doenças, entre outros. Ao longo do tempo essas alterações podem representar a perda da qualidade do solo. Além de que é provável que a liberação de exsudatos pelas plantas de arroz também altere a comunidade microbiana (Ventura et al., 1984; Fageria \& Baligar, 2003).

$\mathrm{O}$ maior valor do qmic verificado na área de primeiro ano (Tabela 4) provavelmente foi devido às condições mais favoráveis à atividade microbiana; este quociente é influenciado por diversos fatores, como o grau de estabilização do carbono orgânico e o histórico de manejo do solo. As variações em qmic refletem o padrão do aporte de matéria orgânica do solo, a eficiência da conversão do carbono microbiano, as perdas de carbono do solo e a estabilização do carbono orgânico pelas frações minerais do solo. Ele indica se o conteúdo de carbono está se mantendo estável ou variando de acordo com as condições impostas ao sistema (Tótola \& Chaer, 2002). Em ecossistemas estáveis, nos quais predominam condições favoráveis, há tendência de aumento da atividade microbiana e, em consequência, o qmic tende a crescer até atingir um nível de equilíbrio (Insam \& Domsch, 1988).
A relação NBM:N total oferece uma estimativa da quantidade de nutriente, disponibilidade de substrato e a dinâmica da matéria orgânica no solo pois, quanto maior seu valor melhor será a qualidade da matéria orgânica (Coser et al., 2007). Uma vez que o nitrogênio total foi semelhante entre as áreas, o maior valor deste atributo na área de primeiro ano é devido ao NBM. Os micro-organismos diferem muito mais no seu teor de nitrogênio do que no de carbono, dependendo do seu estágio de desenvolvimento. Portanto, pequenas mudanças na estrutura da biomassa microbiana podem resultar em grandes mudanças no NBM (Coser et al., 2007). Como já discutido, o maior acúmulo de exsudatos liberados pelas plantas de arroz (Ventura et al., 1984; Fageria \& Baligar, 2003) e o maior número de aplicações de glifosato nas áreas de segundo e terceiro cultivo de arroz podem ter alterado a atividade e a composição da comunidade microbiana, como constataram Andréa et al. (2003) e Zilli et al. (2008), afetando NBM.

A análise de agrupamento aplicada aos atributos do solo confirmou a separação entre as áreas sendo formados três grupos com uma distância euclidiana média de aproximadamente 6 (Figura 1). A área de primeiro ano formou um grupo e as de segundo e terceiro anos de cultivo de arroz formaram outro grupo e se mantiveram mais distantes da área de mata.

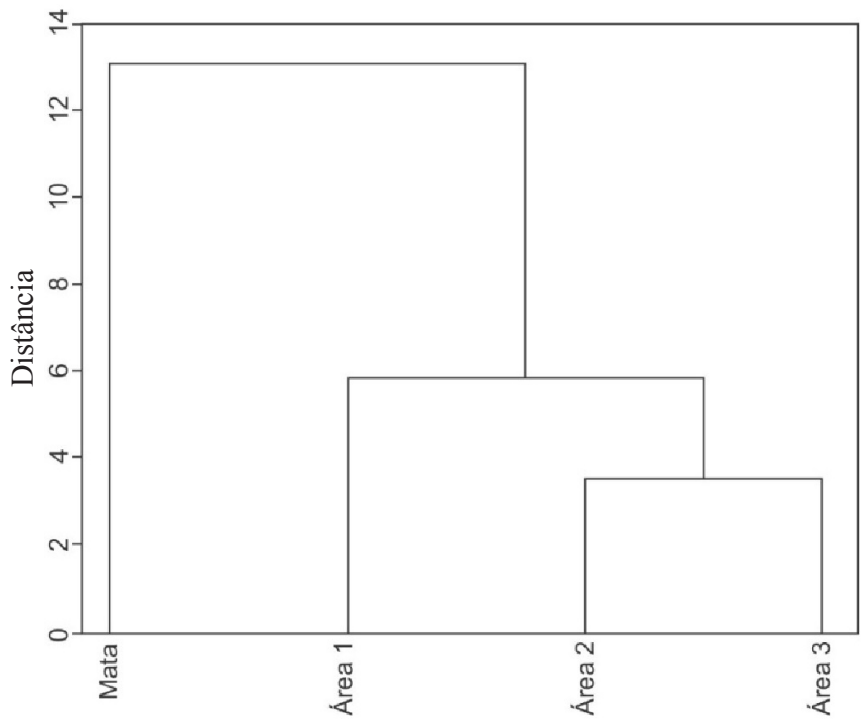

Figura 1. Dendograma de agrupamento das áreas construídas a partir da matriz de distâncias euclidianas médias

\section{Conclusões}

1. Os cultivos de arroz provocaram alterações em todos os atributos físicos e na maioria dos atributos químicos e biológicos do solo, quando comparados com a condição preservada do ambiente de mata.

2. Os teores de potássio, cobre e manganês, os quocientes metabólico e microbiano e a relação nitrogênio da biomassa microbiana:nitrogênio total, foram responsáveis por discriminar as áreas de cultivo sucessivo de arroz.

3. Quanto mais anos de cultivos sucessivos de arroz mais as condições do solo diferiram das do solo original da mata. 
4. O quociente metabólico aumentou com os anos de cultivo de arroz indicando aumento da condição de estresse ou distúrbio na microbiota do solo.

\section{Literatura Citada}

Alleoni, L. R. F.; Cambri, M. A.; Caires, E. F. Atributos químicos de um Latossolo de Cerrado sob plantio direto, de acordo com doses e formas de aplicação de calcário. Revista Brasileira de Ciência do Solo, v.29, p.923-934, 2005.

Andrade, R. da S.; Stone, L. F.; Silveira, P. M. da. Culturas de cobertura e qualidade física de um Latossolo em plantio direto. Revista Brasileira de Engenharia Agrícola e Ambiental, v.13, p.411-418, 2009.

Andréa, M. M. de; Peres, T. B.; Luchini, L. C.; Bazarin, S.; Papini, S.; Matallo, M. B.; Savoy, V. L. T. Influence of repeated applications of glyphosate on its persistence and soil bioactivity. Pesquisa Agropecuária Brasileira, v.38, p.1329-1335, 2003.

Araújo, J. L.; Faquin, V.; Vieira, N. M. B.; Oliveira, M. V. C. de; Soares, A. A.; Rodrigues, C. R.; Mesquita, A. C. Crescimento e produção do arroz sob diferentes proporções de nitrato e amônio. Revista Brasileira de Ciência do Solo, v.36, p.921-930, 2012.

Araújo, R.; Goedert, W. J.; Lacerda, M. P. C. Qualidade de um solo sob diferentes usos e sob cerrado nativo. Revista Brasileira de Ciência do Solo, v.31, p.1099-1108, 2007.

Carneiro, M. A. C.; Souza, E. D. de; Reis, E. F. dos; Pereira, H. S.; Azevedo, W. R. de. Atributos físicos, químicos e biológicos de solo de Cerrado sob diferentes sistemas de uso e manejo. Revista Brasileira de Ciência do Solo, v.33, p.147-157, 2009.

Coser, T. R.; Ramos, M. L. G.; Amabile, R. F.; Ribeiro Júnior, W. Q. Nitrogênio da biomassa microbiana em solo de Cerrado com aplicação de fertilizante nitrogenado. Pesquisa Agropecuária Brasileira, v.42, p.399-406, 2007.

Coutinho, C. F. B.; Mazo, L. H. Complexos metálicos com o herbicida glifosato: Revisão. Química Nova, v.28, p.10381045, 2005.

Cruz, C. D.; Regazzi, A. J. Modelos biométricos aplicados ao melhoramento genético. Viçosa: UFV, 1994. 390p.

Cruz-Castilho, J. G.; Ganeshanandam, S.; Mackay, B. R.; Lawes, G. S.; Lawoko, C. R. O. O.; Woolley, D. J. Applications of canonical discriminant analysis in horticultural research. HortScience, v.29, p.1115-1119, 1994.

Dexter, A. R. Soil physical quality. Part 1. Theory, effects of soil texture, density, and organic matter, and effects on root growth. Geoderma, v.120, p.201-214, 2004.

EMBRAPA - Empresa Brasileira de Pesquisa Agropecuária. Centro Nacional de Pesquisa de Solos. Manual de métodos de análise de solos. 2.ed. Rio de Janeiro: Embrapa CNPS, 1997. 212p. Documentos, 1.

Fageria, N. K.; Baligar, V. C. Upland rice and allelopathy. Communications in Soil Science and Plant Analysis, v.34, p.1311-1329, 2003.

Ferreira, E. P. B.; Wendland, A.; Didonet, A. D. Microbial biomass and enzyme activity of a Cerrado Oxisol under agroecological production system. Bragantia, v.70, p.899907, 2011.
George, T.; Magbanua, R.; Garrity, D. P.; Tubaña, B. S.; Quiton, J. Rapid yield loss of rice cropped successively in aerobic soil. Agronomy Journal, v.94, p.981-989, 2002.

Huber, D. M. Efeitos do glifosato em doenças de plantas. In: Simpósio sobre Problemas de Nutrição e de Doenças de Plantas na Agricultura Moderna: Ameaças à Sustentabilidade? 1, 2007, Piracicaba. Anais...Piracicaba: INPI, 2007. CD-Rom

Insam, H.; Domsch, K. H. Relationship between soil organic carbon and microbial biomass on chronosequences of reclamation sites. Microbial Ecology, v.15, p.177-188, 1988.

Jakelaitis, A.; Silva, A. A. da; Santos, J. B. dos; Vivian, R. Qualidade da camada superficial de solo sob mata, pastagens e áreas cultivadas. Pesquisa Agropecuária Tropical, v.38, p.118-127, 2008.

Nunes, L. A. P. L.; Araújo Filho, J. A. de; Holanda Júnior, E. V; Menezes, R. I. de Q. Impacto da queimada e de enleiramento de resíduos orgânicos em atributos biológicos de solo sob caatinga no semi-árido nordestino. Revista Caatinga, v.22, p.131-140, 2009.

Pôrto, M. L.; Alves, J. do C.; Diniz, A. A.; Souza, A. P. de; Santos, D. Indicadores biológicos de qualidade do solo em diferentes sistemas de uso no Brejo Paraibano. Ciência e Agrotecnologia, v.33, p.1011-1017, 2009.

$\mathrm{R}$ Development Core Team. R: A language and environment for statistical computing. Vienna: $\mathrm{R}$ foundation for statistical computing, 2011. http://www.R-project.org. 25 Jan. 2011.

Silva, F. de F. da; Freddi, O. da S.; Centurion, J. F.; Aratani, R. G.; Andrioli, F. F.; Andrioli, I. Propriedades físicas de um Latossolo Vermelho cultivado no sistema plantio direto. Irriga, v.13, p.191-204, 2008.

Silva, S. C. da; Heinemann, A. B.; Paz, R. L. F.; Amorim, A. de O. Informações meteorológicas para pesquisa e planejamento agrícola, referentes ao ano de 2009, do município de Santo Antônio de Goiás, GO. Santo Antônio de Goiás: Embrapa Arroz e Feijão, 2010. 32p. Documentos, 256.

Siqueira Neto, M.; Piccolo, M. de C.; Scopel, E.; Costa Júnior, C. da; Cerri, C. C.; Bernoux, M. Carbono total e atributos químicos com diferentes usos do solo no Cerrado. Acta Scientiarum. Agronomy, v.31, p.709-717, 2009.

Soares, A. A. Desvendando o segredo do insucesso do plantio direto do arroz de terras altas. Informe Agropecuário, v.25, p.58-66, 2004.

Souza, D. M. G. de; Lobato, E; Goedert, W. Manejo da fertilidade do solo no Cerrado. In: Albuquerque, A. C. S.; Silva, A. G. da. (ed.). Agricultura tropical: Quatro décadas de inovações tecnológicas, institucionais e políticas. Brasília: Embrapa Informação Tecnológica, 2008. v.2, p.203-260.

Tótola, M. R.; Chaer, G. M. Microorganismos e processos microbiológicos como indicadores de qualidade dos solos. In: Alvares, V. H.; Schaefer, C. E. G. R.; Barros, N. F.; Mello, J. W. V.; Costa, L. M. (ed.). Tópicos em ciência do solo. Viçosa: Sociedade Brasileira de Ciência do Solo, v.2, p.195-276, 2002. 
Ventura, W.; Watanabe, I.; Komada, H.; Nishio, M.; Cruz, A. de la; Castillo, M. Soil sickness caused by continuous cropping of upland rice, mungbean and other crops. Manila: IRRI, 1984. 13p. Research Paper Series, 99.
Zilli, J. E.; Botelho, G. R.; Neves, M. C. P.; Rumjanek, N. G. Efeito de glyphosate e imazaquin na comunidade bacteriana do rizoplano de soja (Glycine max (L.) Merrill) e em características microbiológicas do solo. Revista Brasileira de Ciência do Solo, v.32, p.633-642, 2008. 